\title{
La colección paremiológica atribuida al Marqués de Santillana y los Refranes de Hernán Núñez
}

Rafael Ernesto Costarelli

UNNE

\section{Resumen}

Este artículo aborda un aspecto no estudiado en la bibliografia paremiológica hispánica: compara el refranero atribuido al Marqués de Santillana con el refranero de Hernán Núnez. Comienza presentando las dos colecciones paremiológicas. Reconstruye aspectos del contexto cultural de producción y consumo de las obras. Examina las relaciones entre los refranes y otras "formas simples". Se detiene en el análisis del proceso de puesta por escrito de los refranes. Compara las dos colecciones en el plano ideológico. El trabajo finaliza con conclusiones que explican las convergencias y divergencias entre ambos textos.

Palabras clave: paremiología-literatura-refranes

En el año 1508 se imprimió en Sevilla un pequeño volumen con el siguiente encabezado: "Iñigo Lopez de Mendoza a ruego del rrey don Juan ordeno estos refranes que dizen las viejas tras el fuego y van ordenados por el orden del a. b. c." (p. 77) . $^{21}$. La colección atribuida al marqués de Santillana puede considerarse un hito en la historia de la paremiología hispánica y un gozne entre la paremiología medieval y las colecciones españolas de refranes de los siglos XVI y XVII.

Ya han sido sefialados los enlaces entre el refranero del marqués de Santillana y la obra de Mosén Pedro Vallés, del año 1549, conocida como Libro de refranes. Julia Sevilla (1992: 112-113) ha indicado que las dos colecciones coinciden en tener intención didáctica y en ser cuantitativas y alfabéticas, aunque la de Vallés refleja cierta tendencia erasmista, pues incluye refranes de tipo satírico. Más allá de estos esbozos, creemos que la tarea fundamental de la comparación ideológica entre ambas colecciones está por realizarse.

En el presente trabajo trataremos de establecer relaciones entre la colección del Marqués de Santillana y otra colección paremiológica del siglo XVI tanto o más importante que la de Vallés: los Refranes o proverbios en romance, de Hernán Núnez, obra publicada por León de Castro en 1555. Creemos que ambas colecciones comparten el mismo núcleo ideológico y son contribuciones insoslayables a lo que tenemos institucionalizado como colección de refranes o libro de refranes, es decir, un tipo de texto aprovechable en una lectura ocasional.

A un nivel superficial, las dos compilaciones comparten el haber sido ordenadas alfabéticamente y el haber sido tituladas como 'refranes' 22 . Veremos cómo, detrás de estas coincidencias exteriores, hay profundas convergencias de fondo, $y$ algunas divergencias, que explican cómo intervinieron por selección los compiladores.

Para desarrollar la comparación seguiremos cuatro pasos:

${ }^{21}$ Edición de Hugo Bizzarri, 1995.

${ }^{22}$ El padre Sbarbi registraba en su conocida Monografia (1891) cuarenta y ocho colecciones paremiológicas cuyo título comenzaba con el vocablo 'refranes'. Hoy se ha extendido el uso del vocablo 'refranero' para titular las colecciones (vid. n. 12). 
1. Reconstruiremos algunos aspectos del contexto cultural de producción y consumo de las obras.

2. Examinaremos algunos aspectos vinculados con la forma de los refranes en lo atinente a su puesta por escrito y a su relación con otras "formas simples".

3. Compararemos los dos refraneros en el plano ideológico.

4. Arribaremos a una sintesis.

1 Las colecciones de Santillana y Núnez pertenecen a las denominadas "colecciones alfabéticas" de refranes (Bizzarri, 2004: 114). Esta antigua forma de disponer una seriación paremiológica es de procedencia escolar y fue valorada por su utilidad a la hora de hallar una paremia. Una vez generalizado su uso en la enseñanza, durante la Edad Media, se trasladó a otros dominios, como la predicación. Se distingue de otras formas de disponer el material paremiológico: a) series de narraciones breves que sirven de marco a un refrán para contextualizar su uso, explicar su significado o situarlo en un posible origen, como las de Timoneda $(1563)^{23}$, Santa Cruz $(1574)^{24}$ y Rufo $\left.(1596)^{25} ; b\right)$ colecciones de refranes glosados, como la de Mal Lara (1568); c) colecciones de paremias en versos enhebrados anafóricamente, como la de Barros $(1598)^{26}$.

En resumen, ni el Marqués de Santillana ni Hernán Núñez inventaron la forma de elaborar sus refraneros, sino que adoptaron una técnica escolar ya canonizada. Sólo ocasionalmente Núfiez glosa algunos de sus refranes, marcando quiebres entre el saber culto y el popular.

La reprobación moral se volcó sobre ambas colecciones. En Valladolid, en 1541, se comentan los Refranes que dizen las viejas tras el fuego para darles un sentido cristiano, porque al glosador le chocaba el realismo que predicaban las paremias (Bizzarri, 2004: 109-110). La colección de Núnez, por su parte, fue duramente atacada por el padre Feijoo y calificados sus refranes de "... maldicientes, escandalosos, sacrilegos, porque son infamantes de los eclesiásticos..." (p. 555b) ${ }^{27}$.

Ambas colecciones han sido acogidas por un mismo tipo de lector y de mercado: una burguesía que se entretiene con la lectura ocasional de obras breves (Bizzarri, 2004: 69). Resulta ilustrativo de este tipo especial de público y de lectura el título que Juan de Timoneda puso al librito que además de cuentos incluye una breve colección paremiológica en forma narrativa: El sobremesa y alivio de caminantes.

Este nuevo mercado editorial generó la elaboración de repositorios de refranes cada vez más ambiciosos, como el de Correas en el siglo XVII y los de Machado, Sbarbi, Montoto, Sacristán, Melchor García y Rodríguez Marín en épocas más cercanas a la nuestra.

\footnotetext{
${ }^{23}$ La que manejo es la única edición moderna conocida; está en la Biblioteca dẹ Autores Españoles, en el tomo tercero, que lleva el rótulo "Novelistas anteriores a Cervantes".

${ }^{24}$ Manejo una edición en la que no se identifica el nombre de quien fijó el texto y realizó las notas.

${ }^{2 s}$ Edición, prólogo y notas de Alberto Blecua, 1972.

${ }^{26}$ Colección ordenada por D. Adolfo de Castro, 1951.

${ }^{27}$ Edición de D. Vicente de la Fuente, 1952.
} 
2 Al enfrentarnos con las colecciones de Santillana y de Núnez debemos tener en cuenta que leeremos en ellas refranes "literarios", es decir, versiones escritas del refrán popular. Deberemos considerar, asimismo, que hallaremos compiladas, como refranes y junto con ellos, a otras "formas simples" de estrecho parentesco: cantares, sentencias, adivinanzas, etc. Encontraremos también en las paremias características propias del "refrán literario", como la rima (Bizzarri, 2004: 34-35).

En las dos colecciones observamos versos proverbializados, aunque la presencia de estos cantares es algo más frecuente en la colección de Núnez ${ }^{28}$. El siguiente refrán cantado aparece recogido en la colección de Santillana: "Quien bien tiene y mal escoje por mal que le venga no se enoje" (p. 105, núm. 622). Leemos otro caso de refrán cantado en la colección de Núfíez: "A los años mil, vuelve el agua por do solía ir" (p. 17) ${ }^{29}$.

En la colección de Núfiez es posible hallar también, propuestos como entretenimiento: adivinanzas, enigmas y diversos juegos de palabras. Como curiosidad anotamos una composición con función mnemónica sobre los meses del año, que aún se comunica, con variantes formales, y constituye una supervivencia: "Treinta trae Noviembre, Abril y Junio y Septiembre, veintiocho trae uno, los otros a treinta y uno" (p. 191).

La sedimentación, es decir, el agregado de una coda que explicita el sentido del refrán (Bizzarri, 2004: 47) como resultado de un proceso propio de la puesta por escrito, no sólo se observa en las sucesivas ediciones de la colección del Marqués de Santillana. Se observa cuando examinamos los mismos refranes en la obra del Marqués y en la de Núfiez. Veamos un caso recogido en la colección del Marqués: "El fisico de Orgaz que cataua el pulso en el onbro" (p. 89, núm. 285). Se lee aumentado en la colección de Núnez: "El fisico de Orgaz, que cataba el pulso en el hombro y las orinas en el mortero" (p. 76). Cada vez más alejadas del contexto natural, en el que se sabía que se hablaba de un mal médico, las paremias necesitan adiciones y extensiones para ser comprendidas. Este proceso de sedimentación se intensifica en la colección de Correas, lo que disminuye un poco el valor de su esfuerzo por transcribir fonéticamente las paremias ${ }^{30}$.

Como parte del proceso de la puesta por escrito, se va optando por versiones de refranes con rima. En la obra del Marqués aparece en versión sin rima el siguiente refrán: "A buen entendedor pocas palabras" (p. 80, núm. 78). Pero se lee con rima en la obra de Núñez: " $A$ buen entendedor, breve hablador" (p. 8).

3 Entre la colección del Marqués de Santillana y la de Hernán Núnez se pueden concordar, en números redondos, más de trescientos refranes, admitiendo en el cotejo algunas variantes formales. Más del cuarenta por ciento de los refranes compilados por el Marqués, que suman setecientos veinticinco, se encuentran en la colección de Núñez.

${ }^{28}$ Sobre el tema no puede soslayarse el trabajo ya clásico de Margit Frenk (1978).

${ }^{29}$ Manejo una edición no reseffada en la bibliografia paremiológica, titulada Refranero español y que sigue a la princeps de 1555 en el orden de exposición de las paremias, aunque suprime los adagios franceses e italianos.

${ }^{30}$ Edición de Louis Combet, 1967. 
En un proceso abductivo, las paremias de ambas colecciones pueden adscribirse, en general, a las mismas ideas, con diferencias que trataremos en lo subsiguiente ${ }^{31}$.

En casi todos los casos, las ideas que el refranero del Marqués condensa en una o dos paremias son desplegadas a través de varias de ellas en la colección de Núnez. Por ejemplo, al presentar la idea general de la 'acomodación', las dos colecciones concuerdan en una paremia: "Ve do vas, como vieres assi fas" (Santillana, p. 108, núm. 705); "Ve do vas, como vieres así haz" (Núnez, p. 195). Sin embargo, la colección del Comendador despliega más la idea a través de diferentes variantes semánticas: "En cada tierra, su uso" (p. 96); "Mudado el tiempo, mudado el pensamiento" (p. 139). Lo mismo se observa en casi todas las ideas: generales y particulares.

A partir de la comparación realizada podemos decir que ambas colecciones comparten la misma tendencia ideológica: recogen una "philosophía vulgar" que aconseja con cierto amoralismo la conservación del individuo (Bizzarri, 2004: 119), previniendo o disminuyendo enfrentamientos y enseñando cómo actuar y cómo vivir. Además de la idea de 'acomodación', otras del mismo tenor, como la 'precaución' y la 'previsión', contribuyen a formar el núcleo de la prédica de ambas obras. En las dos colecciones, por ejemplo, aparece recogido un refrán que con total amoralidad da a entender que con sobornos se pueden vencer las mayores dificultades: "Dadiuas quebrantan peñas" (Santillana, p. 84, núm. 184); "Dádivas quebrantan peñas" (Núnez, p. 46).

La obra del Marqués de Santillana llega a un extremo más avanzado que la de Núnez al recoger refranes sobre peculiaridades psicológicas y valores humanos. Recordemos una paremia sobre la lealtad que aparece únicamente en su impreso: "Quien en ty se enfia no le engañes" ( $p$. 103, núm. 576).

Núnéz, en cambio, va más lejos en la presentación del mundo externo, que resulta ser abigarrada y heterogénea. Incluye refranes sobre los animales, el tiempo, la naturaleza y el mundo, es decir, los dominios que Mal Lara enuncia en los Preámbulos de la Philosophía vulgar y que quedan sin refranes glosados (p. 57) $)^{32}$. Sus refranes nos brindan consejos sobre agricultura, un detallado almanaque rural y un mapa fisico y moral de la España de su tiempo. Recordemos dos ejemplos: "En tierra seca, el agua salobre es buena" (p. 100); "Ebro traidor, naces en Castilla y riegas á Aragón" (p. 66). Muchos de los refranes recogidos por él serán glosados por Sorapán de Rieros en su Medicina española contenida en proverbios vulgares de nuestra lengua $(1615)^{33}$.

En la obra de Santillana y en la de Núnez se encuentran refranes que evocan el vocabulario de la plaza pública, como el siguiente: "Por el dinero baila el perro" (Santillana, p. 101, núm. 539 y Núñez, p. 158), que probablemente haya tenido su sentido inicial en los pedidos que los adiestradores de animales hacían al público para iniciar un espectáculo. Sin embargo, las imágenes escatológicas y de lo inferior corporal con algunos rasgos de la lengua

\footnotetext{
${ }^{31}$ Utilizo la categorización ideológica realizada por Ezequiel Martínez Kleiser en su Refranero general ideológico español (1953).

${ }^{32}$ Edición y prólogo de Manuel Bernal Rodriguez, 1996.

${ }^{33}$ Edición de José María Sbarbi, 1875. No existen ediciones críticas modernas. El libro merece una esmerada anotación filológica.
} 
carnavalesca sólo se leen en los refranes de Núfiez: "El estiércol no es santo, mas do cae hace milagro" (p. 87).

Núnez se ha inmortalizado por dar lugar en su colección a muchos refranes que expresan ideas en contra de los religiosos, como en estos casos: "Abad avariento, por un bodigo pierde ciento" (p. 8); "El clérigo y el fraile, al que han menester llaman compadre" (p. 78). En la colección del Marqués sólo hallamos un caso que trata de las monjas: "Amor de monjas, fuego de estopas" (p. 79, núm. 72).

4 La afinidad entre la colección de refranes atribuida al Marqués de Santillana y la de Hernán Núfiez es mayor de lo que aparentemente puede parecer, como lo hemos tratado de demostrar. Las dos son hitos en la institucionalización de lo que conocemos como libro de refranes "para en plaza"34. Recordemos que el texto de Núnez fue publicado con el rótulo general de Refranero español.

Las divergencias en el tratamiento de las formas se explicarían por la distancia de épocas entre una colección y otra: más de cincuenta años. En Núnez se había afianzado mucho el proceso de puesta por escrito de los refranes, y la exaltación de la "philosophía vulgar" venía ya a coincidir con la de la lengua vulgar y la de diversos géneros populares de arte verbal. Por eso sus "refranes literarios" son más elaborados y están acompañados por una gran diversidad de "formas simples" de estrecho parentesco. Aunque el libre pasaje de unas formas a otras se observaba en la paremiología medieval, las motivaciones de fondo son distintas. No obstante, cada colección conserva un encanto peculiar en función de las formas. La mayor brevedad de las formas le otorga a la colección del Marqués un estilo conciso y arcano, lo que resalta frente al colorido y la variedad de la colección de Núnez.

La conformidad de ideas entre ambas colecciones nos muestra cómo intervinieron los dos compiladores para contribuir a una "philosophía vulgar" de rasgos realistas, que exalta lo inmanente frente a lo trascendente. Sin embargo, en esta contribución se destaca más Núfiez por el mayor desarrollo de ideas. En ese sentido, la lección del Marqués tiene la función de un preludio en el amanecer renacentista.

Por consiguiente, las observaciones aquí anotadas nos permiten finalizar afirmando que entre las dos colecciones existe un marcado paralelismo con divergencias claramente explicables.

\section{Referencias}

BARROS, Alonso de. Proverbios Morales o Heráclito, en Poetas líricos de los siglos XVI y XVII, colección ordenada por Don Adolfo de Castro. BAE, t. 42, Madrid, Atlas, 1951, pp. 231240.

BIZZARRI, Hugo O. El refranero castellano en la Edad Media. Madrid, Ediciones del Laberinto, 2004.

\footnotetext{
${ }^{34}$ Hoy, más que la de acervo paremiológico, la acepción más aceptada del vocablo 'refranero' es la de 'colección de refranes', tal es la que presenta el Diccionario de la Real Academia Espafiola en su última edición.

${ }^{35}$ Ver el título de la edición de Núnez que manejamos para elaborar este trabajo.
} 
CORREAS, Gonzalo. Vocabulario de refranes y frases proverbiales (1627), edición de Louis Combet. Université de Bordeaux, 1967.

FEIJOO, Benito Jerónimo. "Falibilidad de los adagios", en Obras Escogidas del Padre Feijoo, edición de Vicente de la Fuente. BAE, Vol. 56, Madrid, Atlas, 1952, pp. 552-555.

FRENK, Margit. "Refranes cantados y cantares proverbializados", en Estudios sobre lirica antigua. Madrid, Castalia, 1978.

LÓPEZ DE MENDOZA, Iñigo (Marqués de Santillana). Refranes que dizen las viejas tras el fuego, edición crítica de Hugo Bizzarri. Edition Reichenberger, Kassel, 1995.

MAL LARA, Juan de. Obras Completas, I: Philosophía Vulgar (1568), edición y prólogo de Manuel Bernal Rodríguez. Madrid, Ediciones de la Fundación José Antonio de Castro, 1996.

MARTINEZ KEISER, Ezequiel. Refranero general ideológico español. Madrid, Real Academia Española, 1953.

NÚÑEZ, Hernán. Refranero Español [Refranes o proverbios en romance (1555)]. Valencia, Prometeo, s.a.

RUFO, Juan. Las seiscientas apotegmas y otras obras en verso (1596), edición, prólogo y notas de Alberto Blecua. Madrid, Espasa-Calpe, 1972.

SEVILLA MUÑOZ, Julia. "Fuentes paremiológicas francesas y espanfolas en el siglo XVI", en Revista de Filología Románica, 9 (1992), Madrid, Editorial Complutense, pp. 103-123.

SANTA CRUZ DE DUEÑAS, Melchor de. Floresta Española (1574). Buenos Aires-México, Espasa-Calpe, $1947,2^{\mathrm{a}}$ edición.

SBARBI, José María. Monografia sobre los refranes, adagios y proverbios castellanos. Madrid, Imprenta y litografia de los huérfanos, 1891.

SORAPAN DE RIEROS, Iván. Medicina española contenida en proverbios vulgares de nuestra lengua (1615), en José María Sbarbi (ed.), El Refranero general español, VIII. Madrid, Imprenta de A. Gómez Fuentenebro, 1875; pp.3-299.

TIMONEDA, Juan de. El sobremesa y alivio de caminantes, en Novelistas anteriores a Cervantes, ordenada e ilustrada por D. Buenaventura Carlos Aribau. BAE, t.3, Madrid, Atlas, 1944, pp. 166-183.

Rafael Costarelli se desempeña actualmente como profesor adjunto en la cátedra de "Literatura Española II" en la Facultad de Humanidades de la Universidad Nacional del Nordeste. Desde el mes de noviembre de 2007 trabaja con el grupo de la Universidad Nacional del Sur, dirigido por la Dra. Alicia Ramadori, que investiga el uso de sentencias y refranes en textos literarios. Es licenciado en Letras y magíster en Filología Hispánica por el Consejo Superior de Investigaciones Cientificas de España. Su tesis de maestría, dirigida por la Dra. Paloma DíazMas, versó sobre la Antroponimia en la antigua lírica tradicional hispánica y recibió la máxima calificación, sobresaliente cum laude. 